\title{
Needs Assessment of the Participants of Computer Literacy Program (CLIP) in Partner Community
}

\author{
Julian N. Semblante * \\ Mauro Allan P. Amparado ** \\ University of Cebu Lapu-Lapu and Mandaue \\ Mandaue City, Cebu, Philippines
}

* Program Coordinator, College of Computer Studies, juliansemblante@gmail.com

** Director, Community Awareness, Relations \& Extension Services, mapamparado@gmail.com

\section{Abstract}

Determining the needs of the participants in a community extension program prioritizes the topics that they will be interested to attend. This ensures that participants are motivated and interested in various topics presented in the program. The study assessed the needs of participants from Village Looc, Mandaue City, Cebu, Philippines, on the computer literacy program (CLIP) offered by the UCLM College of Computer Studies. The findings of the study were the basis for a proposed annual extension program plan for June 2018 to May 2019.

Findings revealed that the top ten needs were: computer assembly, computer troubleshooting, Microsoft Word, Microsoft Powerpoint, Internet cable termination, game development, web design, mobile application, keyboarding, and hard disk installation.

Determining the needs of the participants prioritizes the topics that they will be interested to attend. This ensures that participants are motivated and interested in various topics presented in the computer literacy training program. 
Keywords: Computer assembly; computer troubleshooting; Microsoft Word; Microsoft Powerpoint; Internet cable termination

Recommended citation: Semblante, J. A. \& Amparado, M. A. P. (2020). Needs Assessment of the Participants of Computer Literacy Program (CLIP) in Partner Community. Cebu Journal of Computer Studies, 2(1), 91-100.

\section{Introduction}

Today's youth could definitely be called the computing generation. Baby boomers may have been introduced to computers at college or on the job, and older people may never have used a computer until after retirement, if at all, but many of today's young people have been brought up with computing technology. From video games to computers at school and home, most children and teens today have been exposed to computers and related technology all their lives. Although the amount of computer use varies from school to school, students in elementary and secondary schools typically have access to computers either in the classroom or in a computer laboratory, and virtually all colleges have some sort of computing facility available for student use (Morley \& Parker, 2007).

Some of the most prominent policies in schools throughout the industrialized world today relate to the rapid introduction of computers. The most common rationale for introducing educational microcomputing is the concept of 'computer literacy'. It is a concept, however, which is so poorly defined and delineated, and so unclear as to purpose and procedure, that it may best be investigated as a form of ideology. The justificatory arguments for computers in classrooms are primarily vocational or practical. They are based on assumptions that computers will be pervasive in the workplace of the future, or that they are soon going to be 'everywhere'. The more purely pedagogical arguments are 
secondary: that learning about computers is a worthwhile experience in and of itself, and that computers can be useful productivity tools for other academic work (Goodson \& Mangan, 1996).

In addition to curiosity (and perhaps a course requirement), a person will recognize that it will not be easy to get through the rest of life without knowing about computers. Computer literacy may be three-pronged defined: awareness, knowledge and interaction. As one studies about computers, the person becomes aware of the importance, versatility and its pervasiveness in the society. The person will also learn what computers are and how they work. This requires learning some technical jargon. And there is no better way to understand computers than through interacting with one. So being computer literate also means being able to use a computer for some simple applications (Capron \& Johnson, 2004).

Today, it is easy for nearly everybody to use a computer. Microcomputers are common tools in all areas of life. Writers write, artists draw, engineers and scientists calculate using microcomputers. Students and business people do all this and more. New forms of learning have developed. People who are homebound, who work odd hours, or who travel frequently may take Web courses. A college course need not fit within a quarter or a semester. New ways to communicate to find people with similar interests, and to buy goods are available. People use electronic mail, electronic commerce, and the Internet to meet and to share ideas and products (O' Leary \& O' Leary, 2011).

Many people believe that computer literacy is vital to success. Computer literacy, also known as digital literacy, involves having a current knowledge and understanding of computers and their uses. Because the requirements that determine computer literacy changes as technology changes, you must keep up with these changes to remain computer literate (Shelly \& Vermaat, 2011). 
The mission of University of Cebu Lapu-Lapu and Mandaue is to pursue excellence in instruction, research, and community service towards social and economic development as well as environmental sustainability (Amparado, 2013). The university also funded a community needs assessment study conducted by Amparado, Camayra, Dorio and Patindol (2017). The researchers identified the sustainable community extension programs for Village Looc, Mandaue City, Cebu, Philippines. They discovered that in 2008, the needs of the community were solid waste management, literacy and livelihood programs. Furthermore, the needs in 2016 were solid waste management, health education, literacy, livelihood, greening, livestock raising, and community participation programs.

As such, it is important to determine the needs of the participants as they undergo ten months of computer literacy training. The results of the study will serve as vital information in the creation of UCLM College of Computer Studies' computer literacy program.

\section{Related Studies}

Various studies have been conducted on literacy needs and computer literacy. In the study of Amparado and Colonia (2020), the researchers have identified that the sustainable programs of the university for Village Opao, Mandaue City shall include literacy, livelihood, backyard gardening, livestock raising, flooding, family planning, administration of tetanus toxoid, and community participation programs.

Another study examined the impact of computer literacy on students' academic performance in Esan West Local Government Area of Edo State, Nigeria. Findings revealed that: computer literate students perform better than non-computer literate; 
computer literate female students perform better than male students who are computer literate; computer literate female students who are not addicted to the use of computer facilities perform better than those who are addicted; computer literate students in co-educational secondary schools perform slightly better than those in single sex schools (Aitokhuehi \& Ojogho, 2014).

In another study, researchers discovered that a successful computer literacy program designed for rural communities would need to work in a diverse set of conditions such as the lack of electricity, diverse student educational backgrounds, motivation levels, different levels of community engagement, community politics, and beliefs (Kantamneni \& Chintalapati, 2013).

\section{Objectives}

The study assessed the needs of participants from Village Looc, Mandaue City, Cebu, Philippines, on the computer literacy program (CLIP) offered by the UCLM College of Computer Studies. The findings of the study were the basis for a proposed annual extension program plan for June 2018 to May 2019.

\section{Methods}

This descriptive, quantitative study was conducted among 40 participants to assess their needs in the Computer Literacy Program. The study was conducted at Village Looc, Mandaue City, Cebu, Philippines which is the partner community of UCLM. Data was collected from May 1, 2018 to May 30, 2018. A twenty item, cafeteria questionnaire was used to assess the needs. This will form part of the proposed annual plan. 


\section{Results and Discussion}

Table 1 presents the needs of the participants in the CLIP Program. The table reveals that the respondents' top ten needs were: computer assembly, computer troubleshooting, Microsoft Word, Microsoft Powerpoint, Internet cable termination, game development, web design, mobile application, keyboarding, and hard disk installation.

Computer Assembly is a training course which teaches the respondents on how to disassemble a computer system, recognize computer components and accessories, assemble the computer system, and test the computer system.

Computer Troubleshooting will guide trainees to recognize common problems of the computer system, identify basic troubleshooting procedures and tools, describe safety hazards involved in working with electronic equipment, and demonstrate the ability to install and effectively use command-line functions and utilities to manage the operating system.

By successfully completing the training course on Microsoft Word, the trainees will be able to learn the newest features of Word; create, edit and save documents; format text and paragraphs; work with tables, columns and other formatting features; and work with graphics, WordArt, charts and text flow.

On the other hand, Microsoft PowerPoint will teach the participants on the newest features of PowerPoint; create presentations with PowerPoint; format and organize PowerPoint slides; work with graphics, tables and charts; add multimedia and SmartArt presentations; and integrate Microsoft office files. 
Internet Cable Termination is designed to terminate and test straight-through, cross-over and roll-over UTP Category $5 \mathrm{e} / 6 \mathrm{e}$ cables.

On the other hand, basic graphics as pre-cursor to game development will teach the trainees to understand and work with layers; enhance images with paint and filters; perform color adjustments; work with vector paths; and automate task. Adobe Photoshop is the software program used in the training.

Web Design Basics with HTML will help the trainees to define the basics in web design, visualize the basic concept of HTML, recognize the elements of HTML, and design a homepage of a website.

Mobile Application (Basic Mobile User Interface Design) teaches the participants to design graphic user interface for mobile applications.

Keyboarding teaches them the components of the computer and keyboard, seating, posture and hand positioning. Rapid Typing software program is used for graphical keyboard drills and keyboarding Self-Tests. The trainees are expected to keyboard at minimum of twenty (20) words per minute.

For hard disk installation, the trainees will be able to configure as a master or slave device (PATA only), mount the drive in the chassis, connect the data cable to the drive and to the PATA or SATA interface, connect a power cable to the driver, restart the system and run the BIOS. 
Table 1. Needs Assessment of CLIP

\begin{tabular}{|l|c|c|}
\hline Indicators & Frequency & Rank \\
\hline Computer assembly & 29 & 1.5 \\
\hline Computer troubleshooting & 29 & 1.5 \\
\hline Microsoft Word & 28 & 5 \\
\hline Microsoft Powerpoint & 28 & 5 \\
\hline Internet cable termination & 28 & 5 \\
\hline Game development & 27 & 6 \\
\hline Web design & 26 & 7.5 \\
\hline Mobile application & 26 & 7.5 \\
\hline Keyboarding & 25 & 9 \\
\hline Hard disk installation & 24 & 10 \\
\hline 2D Animation & 23 & 11.5 \\
\hline Operating Windows 7 & 23 & 11.5 \\
\hline Operating Windows 10 & 22 & 13 \\
\hline Local area network set-up & 20 & 14 \\
\hline Printer installation & 18 & 15 \\
\hline C programming & 16 & 16.5 \\
\hline HTML & 16 & 16.5 \\
\hline Microsoft Access & 15 & 18 \\
\hline Java programming & 14 & 19 \\
\hline Microsoft Excel & 12 & 20.5 \\
\hline Switch configuration & 12 & 20.5 \\
\hline Router configuration & 10 & 22 \\
\hline Python programming & 7 & 23 \\
\hline
\end{tabular}

\section{Conclusion}

Determining the needs of the participants prioritizes the topics that they will be interested to attend. This ensures that participants are motivated and interested in various topics presented in the computer literacy training program. 


\section{Literature Cited}

Aitokhuehi, J. O., \& Ojogho, J. (2014). The impact of computer literacy on students' academic performance in senior secondary schools in Esan West Local Government Area, Edo State, Nigeria. Journal of Education and Human Development, 3(3), 265-270. https://doi.org/10.15640/jehd.v3n3a21.

Amparado, M. A. P. (2013). University of Cebu Research Center Manual. Philippines: University of Cebu.

Amparado, M. A. P., Camayra, M. T., Dorio, P. A. Jr. \& Patindol, D. B. (2017). Sustainable community extension programs for Village Looc, Mandaue City, Cebu, Philippines: The $8^{\text {th }}$ year re-assessment. International Journal of Social Sciences, 19(1), pp. 102-114.

Amparado, M. A. P. \& Colonia, Grace E. (2020). Community Needs Assessment of Village Opao, Mandaue City, Cebu, Philippines. Cebu Journal of Teacher Education, 1(1), 83100.

Capron, H. L. \& Johnson, J. A. (2004). Computers: Electronic Tools for an Information Age. $8^{\text {th }}$ edition. Singapore: Pearson Education South Asia Pte Ltd.

Goodson, I. F., \& Mangan, J. M. (1996). Computer literacy as ideology. British Journal of Sociology of Education, 17(1), 6579.

Kantamneni, R. G. P. \& Chintalapati, R. (2013). Computer Literacy Programs in Rural Communities: Understanding Social Motivators. In 2013 IEEE Fifth International Conference on Technology for Education (t4e2013), pp.53-56. 
https://doi.org/10.1109/T4E.2013.21. 
Morley, D. \& Parker, C. S. (2007). Understanding Computers:

Today and Tomorrow. $11^{\text {th }}$ edition. Singapore: Thomson Course Technology.

O' Leary T. J. \& O' Leary L. I. (2011). Computing essentials 2011 complete: Making it work for you. US: The McGraw-Hill Companies Inc.

Shelly, G. B. \& Vermaat, M. E. (2011). Discovering Computers Fundamentals. Philippine edition. Singapore: Cengage Learning. 